\title{
22. NRM/IRM MEASUREMENTS ON SEDIMENTARY AND IGNEOUS ROCKS FROM LEG 126, IZU-BONIN ARC
}

\author{
Stanley M. Cisowski ${ }^{2}$
}

This paper presents a compilation of the variations in natural remanent magnetization (NRM) and isothermal remanent magnetization (IRM) intensities with exposure to alternating- field (AF) demagnetization, for a group of sedimentary and igneous samples taken from cores drilled during Ocean Drilling Program (ODP) Leg 126. The data are presented in the form of log-log plots where IRM values are plotted on the abscissa axis and NRM values on the ordinate axis. Previous studies have shown that the normalized intensities (NRM/IRM ratios) can sometimes identify samples that have suffered demagnetization or remagnetization, whereas the shapes of the demagnetizing curves can yield information about the size distributions of the remanence carriers (Fuller et al., 1988; Cisowski et al., 1990). Normalization of NRM to IRM may also be useful in ascertaining large changes in the relative strength of the paleofield, particularly during periods when the geomagnetic field is reversing (e.g., Cisowski and Koyama, this volume).

The NRM of each sample was measured on a Molspin sample magnetometer after stepwise static (non-tumbling) AF orthogonal axes demagnetization, at field levels of $15,25,35$, and $50 \mathrm{mT}$. The samples were next exposed to direct current (DC) fields of 300 and $600 \mathrm{mT}$ in an electromagnet and then subjected to the same alternating fields as the NRM, with measurements made after each demagnetizing step. In nearly all cases, the IRM measured after exposure to the 600 -mT direct field was $<5 \%$ higher than the IRM acquired in the same sample at $300 \mathrm{mT}$, and in no cases was a $>10 \%$ increase seen. This indicates that the samples had nearly attained saturation remanence by $600 \mathrm{mT}$ (i.e., that fine-grained hematite is not a major remanence carrier in these samples).

The NRM and IRM responses were measured for a large number of samples from four Leg 126 sites deposited since the last (Brunhes/Matuyama) reversal, where the polarity of the geomagnetic field remained in the normal configuration (Figs. 1-4). Similar data are presented in Figures 5 and 6 for sediments from the same four sites, which were deposited during the preceding Matuyama (reversed) and Jaramillo (normal) polarity intervals. For additional comparisons, NRM vs. IRM demagnetization responses were compiled for mixed polarity sediments of Miocene age (Fig. 7A), and lithified sediments of Oligocene age (Fig. 7B) from Hole 792E. Figure 8A presents NRM vs. IRM data for a variety of igneous and pyroclastic samples of Quaternary (Hole 791B) and Oligocene (Hole 792E) ages, whereas Figure 8B summarizes similar data for basaltic andesites of Oligocene age from Hole 793B.

Figures 1-4 are intended as a data base for primary NRM in unaltered sediments. Because many of the cores from which these sediments were obtained are heavily bioturbated, their coherent NRMs were obviously not acquired instantaneously upon deposition (i.e., as with a detrital remanent magnetism or DRM) but instead were acquired later, probably during compaction. Figure 9 contrasts the

\footnotetext{
${ }^{1}$ Taylor, B., Fujioka, K., et al., 1992. Proc. ODP, Sci. Results, 126: College Station, TX (Ocean Drilling Program).

${ }^{2}$ Department of Geological Sciences, University of California at Santa Barbara, Santa Barbara, CA 93106, U.S.A.
}

NRM/IRM ratios obtained on Leg 126 samples measured after AF demagnetization on cores without significant bedding dip (which were deposited since the Brunhes/Matuyama reversal) with their corresponding inclination values. This figure shows that $88 \%$ of the samples whose variations in inclinations fall within $\pm 15^{\circ}$ of the present field inclination of $\sim 42^{\circ}$ have demagnetized NRM/IRM ratios within a factor of 8 of a median value of 0.0022 . On the other hand, $-70 \%$ of the samples with inclinations beyond the range of normal secular variation have ratios outside this factor 8 range. Assuming that these inclinations do not represent anomalous field behavior, these data suggest that the demagnetized NRM/IRM ratio may be useful as a first-order screen to filter out samples that do not accurately reflect the paleofield during their NRM acquisition.

Many of the demagnetization curves in Figures 1-4 suggest a concave-downward shape. Such demagnetization response can be explained by mixtures of fine (high coercivity) and coarse (low coercivity) magnetic grains, where the high-coercivity fraction dominates NRM behavior (Cisowski et al., 1990). In Figure 5, the more extreme concave downward behavior is also a reflection of the removal of a normal, viscous component of magnetization from those sediments representing the Matuyama reversed chron, as the inclinations of these samples steepened in the reversed sense with progressive demagnetization. The four samples with extremely high initial NRM intensities may be particularly prone to acquiring viscous remanence, as again the vector removed with demagnetization was in the normal sense. Similar behavior has been found in limestones from Southeast Asia (E. Schmidtke, pers. comm., 1989).

Figures $7 \mathrm{~A}$ and $7 \mathrm{~B}$ shows that most of the measured Miocene samples display NRM/IRM ratios an order of magnitude below those of the Oligocene. Although the Miocene samples are generally dominated by higher coercivity carriers, as illustrated by the shorter lengths of their demagnetization curves, similar coercivity spectra in the Pleistocene sediments (Figs. 1-6) did not correspond to reduced normalized intensities. As the Miocene samples with reduced normalized intensities are restricted to depths of $\sim 300-338$ mbsf in Hole $792 \mathrm{E}$, the data may indicate that a period of generally low geomagnetic field intensity existed for at least $1.5 \mathrm{~m} . y$. during the latest middle Miocene (Taylor, Fujioka, et al., 1990, "Site 792" chapter, fig. 36).

Figures $8 \mathrm{~A}$ and $8 \mathrm{~B}$ demonstrate that the NRM/IRM plots are very effective in distinguishing igneous and high-temperature pyroclastic samples that have suffered no more than moderate alteration (solid lines), from highly altered igneous and pyroclastic material (dashed and dotted lines), whether deposited hot or cold. A similar distinction in remanence behavior between igneous samples with unaltered and altered magnetic minerals was observed earlier in igneous rocks from the continents (Cisowski et al., 1990).

\section{ACKNOWLEDGMENTS}

Special thanks to J. Cox, who made many of the laboratory measurements included in this paper. This research was funded by a National Science Foundation grant through a subcontract to the Texas A\&M Research Foundation. 


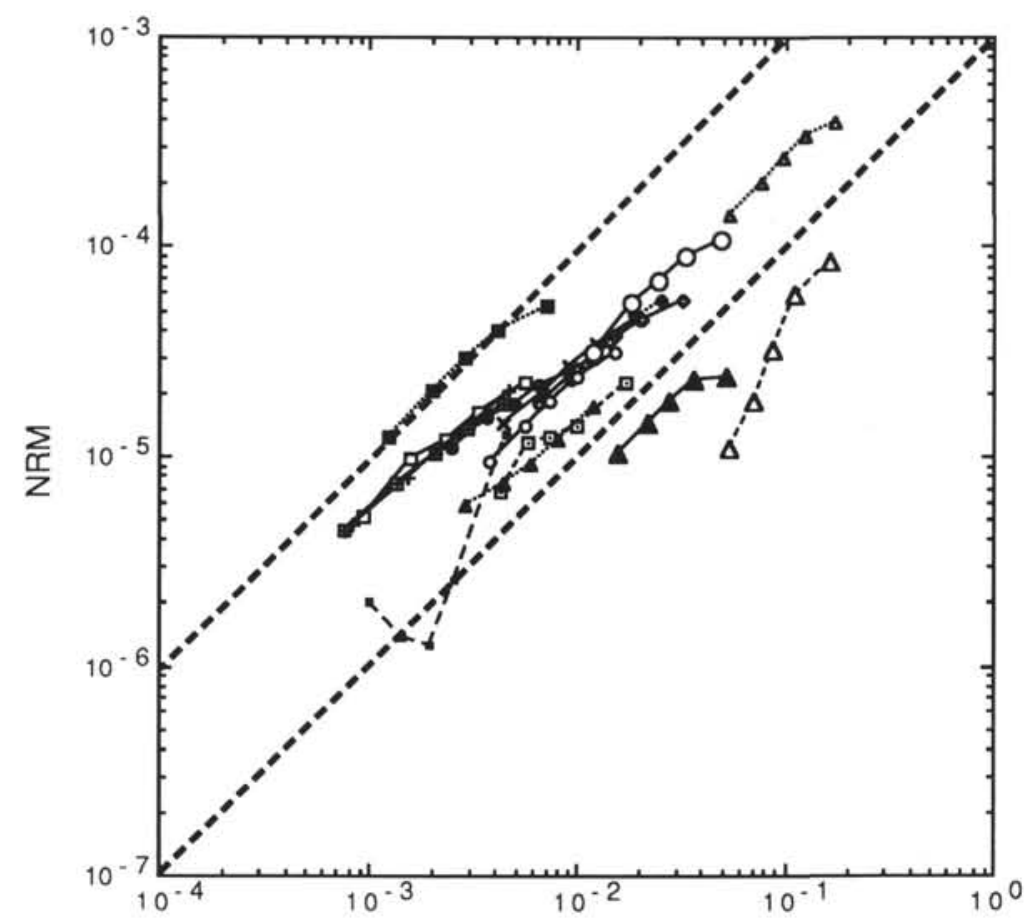

126-790A

--- $-4 \mathrm{H}-1-144,146$

126-790B

$-2 \mathrm{H}-3-23,25$

$\longrightarrow \quad-2 \mathrm{H}-4-112,114$

$\longrightarrow-2 \mathrm{H} \cdot 6-45,47$

………….... $-3 \mathrm{H}-2-59,61$

$\longrightarrow-3 \mathrm{H}-3-108,110$

…….......... -7H-2-115,117

……......... $-8 \mathrm{H}-2-108,110$

$-\cdot-\Delta-\cdots \quad-8 \mathrm{H}-3-18,20$

$\longrightarrow-11 \mathrm{H}-2-138,140$

$\longrightarrow-11 \mathrm{H}-3-12,14$

126-790C

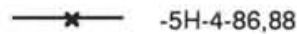

$-\quad-5 \mathrm{H}-5-50,52$

$\longrightarrow \quad-6 \mathrm{H}-3-143,145$

- - - - - $8 \mathrm{H}-3-84,86$

$\longrightarrow \quad-12 X-1-100,102$

IRM

Figure 1. NRM vs. IRM alternating-field (AF) demagnetization responses for sediments deposited during the Brunhes normal polarity chron, Site 790 (burial depths from 8 to $191 \mathrm{mbsf}$ ). Intensities are in $\mathrm{kA} / \mathrm{m}$. Solid lines $=$ clays, dotted lines $=$ silts, dashed lines $=$ sands, dashed diagonal lines $=\mathrm{NRM} / \mathrm{IRM}$ ratios of $10^{-2}$ and $10^{-3}$, respectively.

\section{REFERENCES}

Cisowski, S. M., Dunn, J. R., Fuller, M., and Wasilewski, P. J., 1990. NRM:IRM(s) demagnetization plots of intrusive rocks and the origin of their NRM. Tectonophysics, 184:35-54.

Fuller, M., Cisowski, S., Hart, M., Haston, R., and Schmidtke, E., 1988. NRM:IRM(s) demagnetization plots: an aid to the interpretation of natural remanent magnetization. Geophys. Res. Lett., 15:518-521.
Taylor, B., Fujioka, K., et al., 1990. Proc. ODP, Init. Repts., 126: College Station, TX (Ocean Drilling Program).

Date of initial receipt: 2 January 1991

Date of acceptance: 15 July 1991

Ms 126B-141 


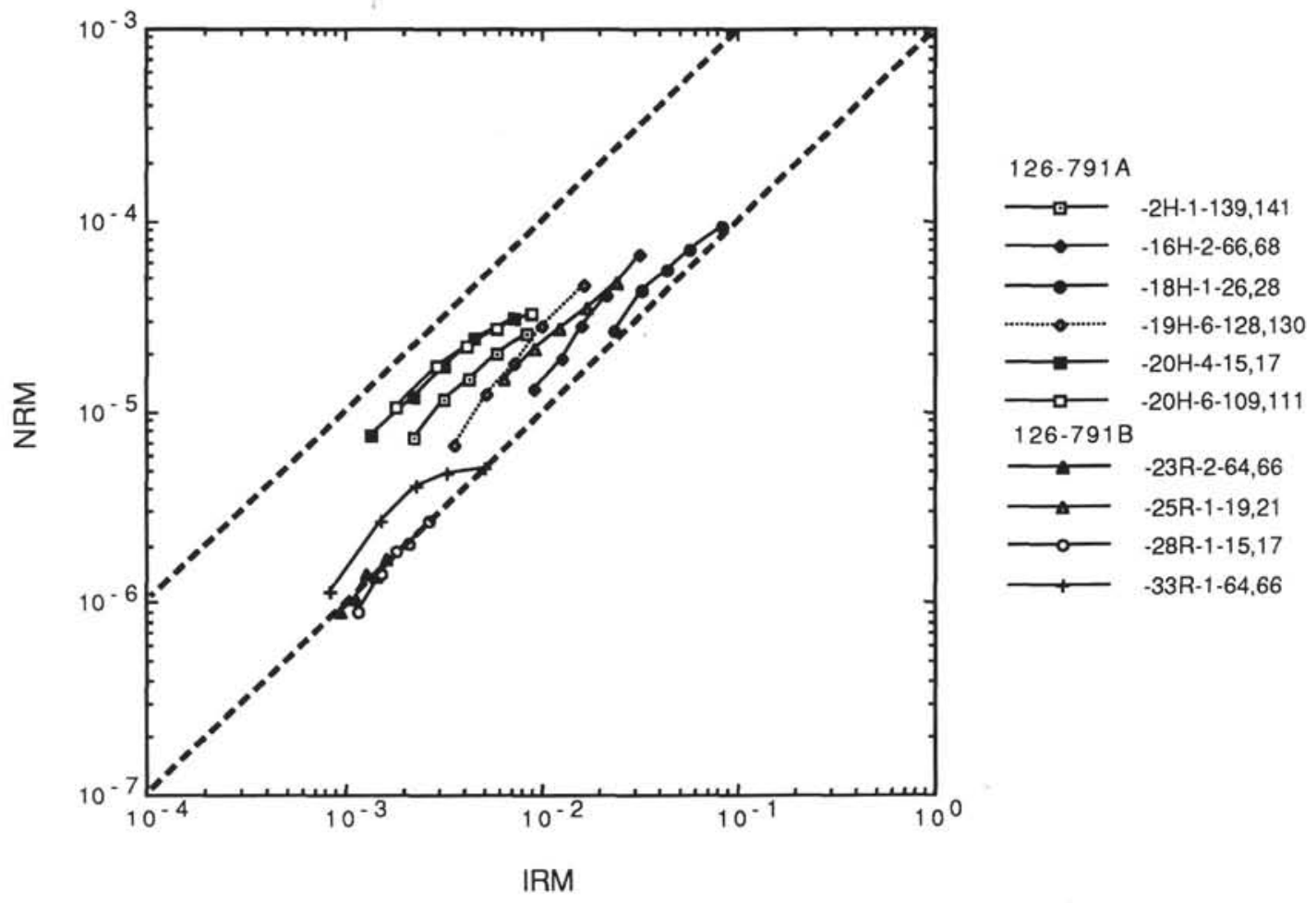

Figure 2. NRM vs. IRM alternating-field (AF) demagnetization responses for sediments deposited during the Brunhes normal polarity chron, Site 791 (burial depths from 6 to $33 \mathrm{mbsf}$ ). Intensities are in $\mathrm{kA} / \mathrm{m}$. Line codes are the same as in Figure 1.

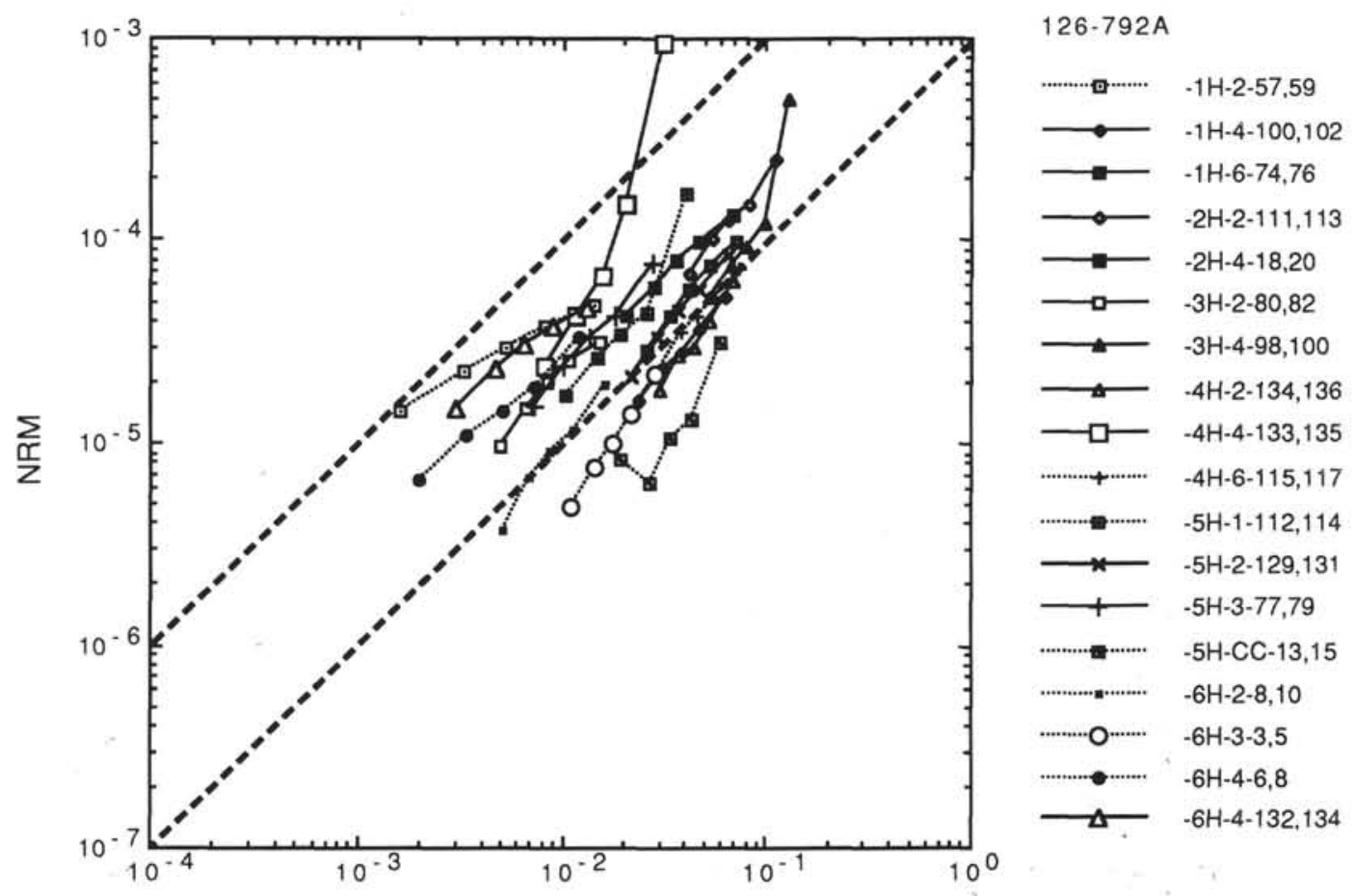

IRM

Figure 3. NRM vs. IRM alternating-field (AF) demagnetization responses for sediments deposited during the Brunhes normal polarity chron, Hole 792A (burial depths from 2 to $55 \mathrm{mbsf}$ ). Intensities are in $\mathrm{kA} / \mathrm{m}$. Line codes are same as in Figure 1. 


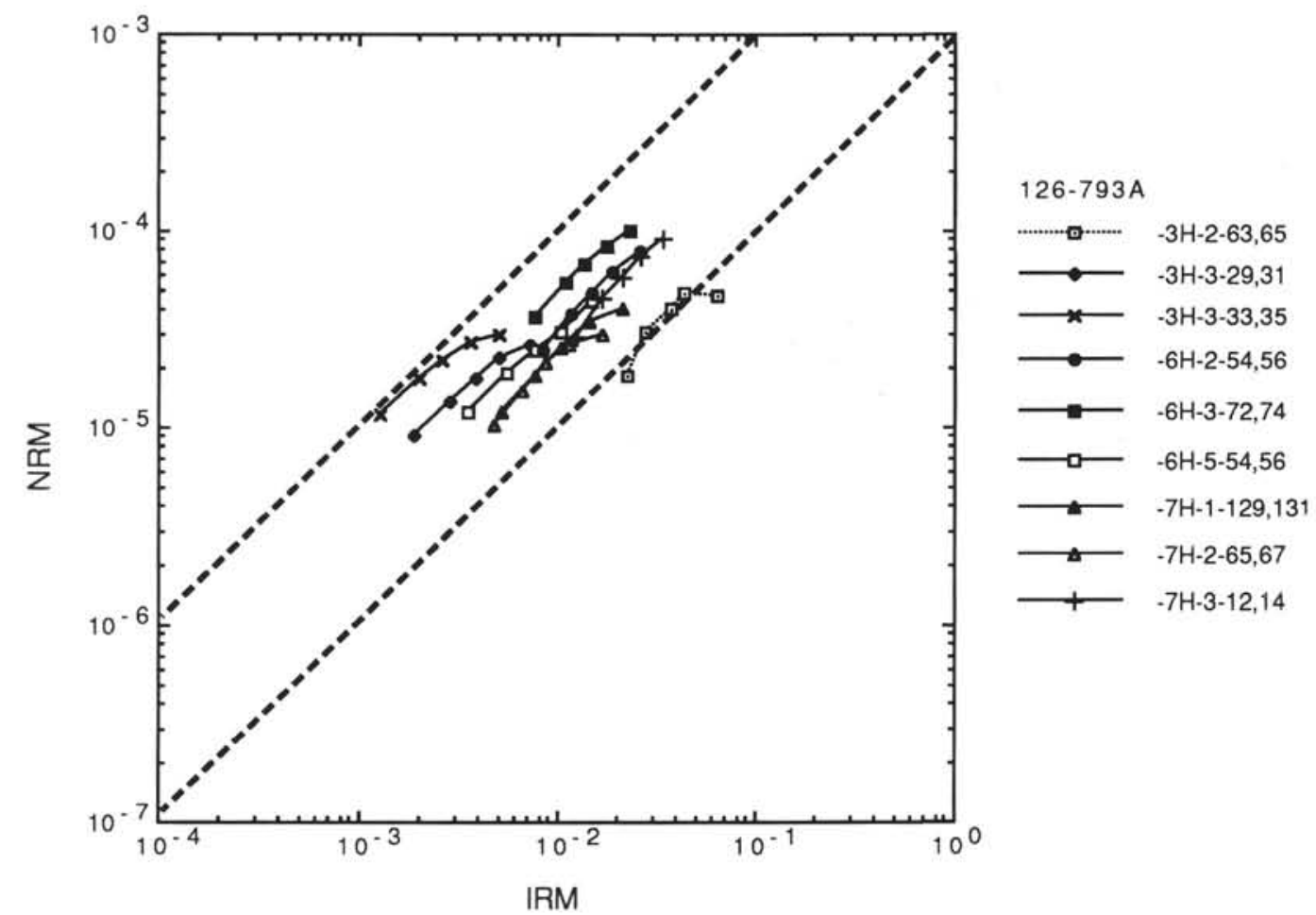

Figure 4. NRM vs. IRM alternating-field (AF) demagnetization responses for sediments deposited during the Brunhes normal polarity chron, Hole 793A (burial depths from 16 to $60 \mathrm{mbsf}$ ). Intensities are in $\mathrm{kA} / \mathrm{m}$. Line codes are same as in Figure 1.

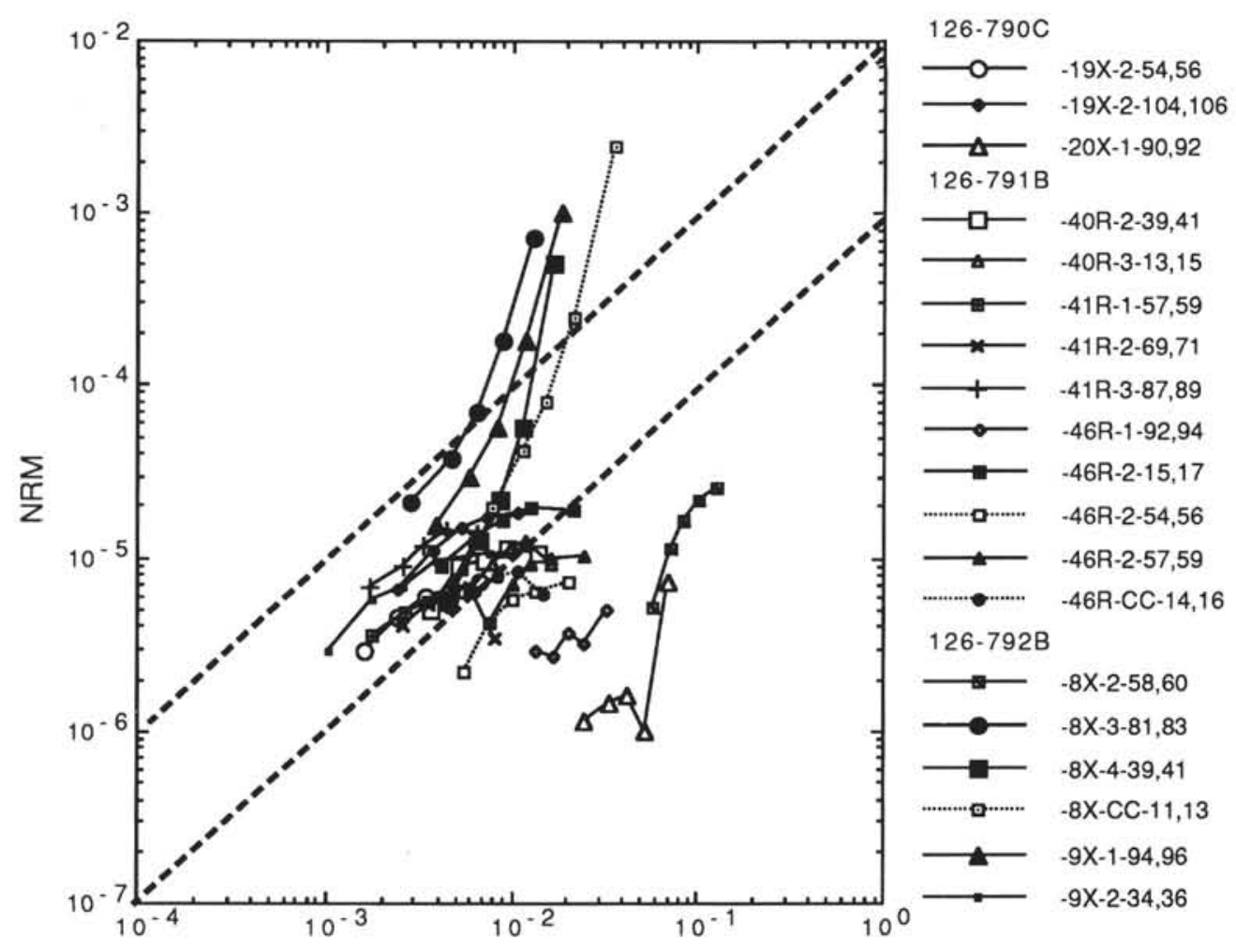

IRM

Figure 5. NRM vs. IRM alternating-field (AF) demagnetization responses for sediments from Holes 790C, 791B, and 792B, deposited during the Matuyama reversed polarity chron (burial depths from 110 to $830 \mathrm{mbsf}$ ). Intensities are in $\mathrm{kA} / \mathrm{m}$. Line codes are same as in Figure 1. 


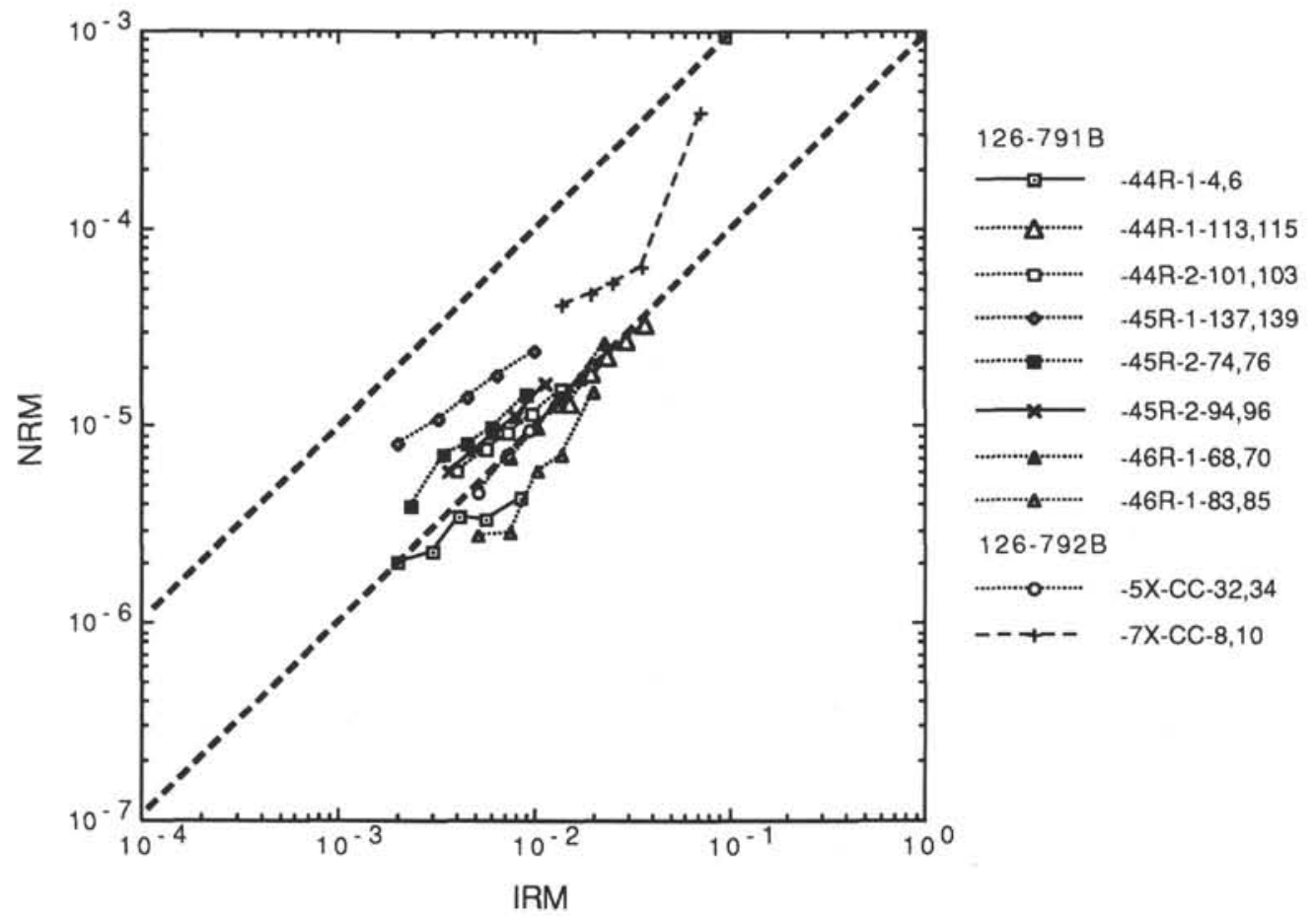

Figure 6. NRM vs. IRM alternating-field (AF) demagnetization responses for sediments from Holes 791B and 792B, deposited during the Jaramillo normal polarity zone (burial depths from 79 to $801 \mathrm{mbsf}$ ). Intensities are in $\mathrm{kA} / \mathrm{m}$. Line codes are same as in Figure 1. 
A.

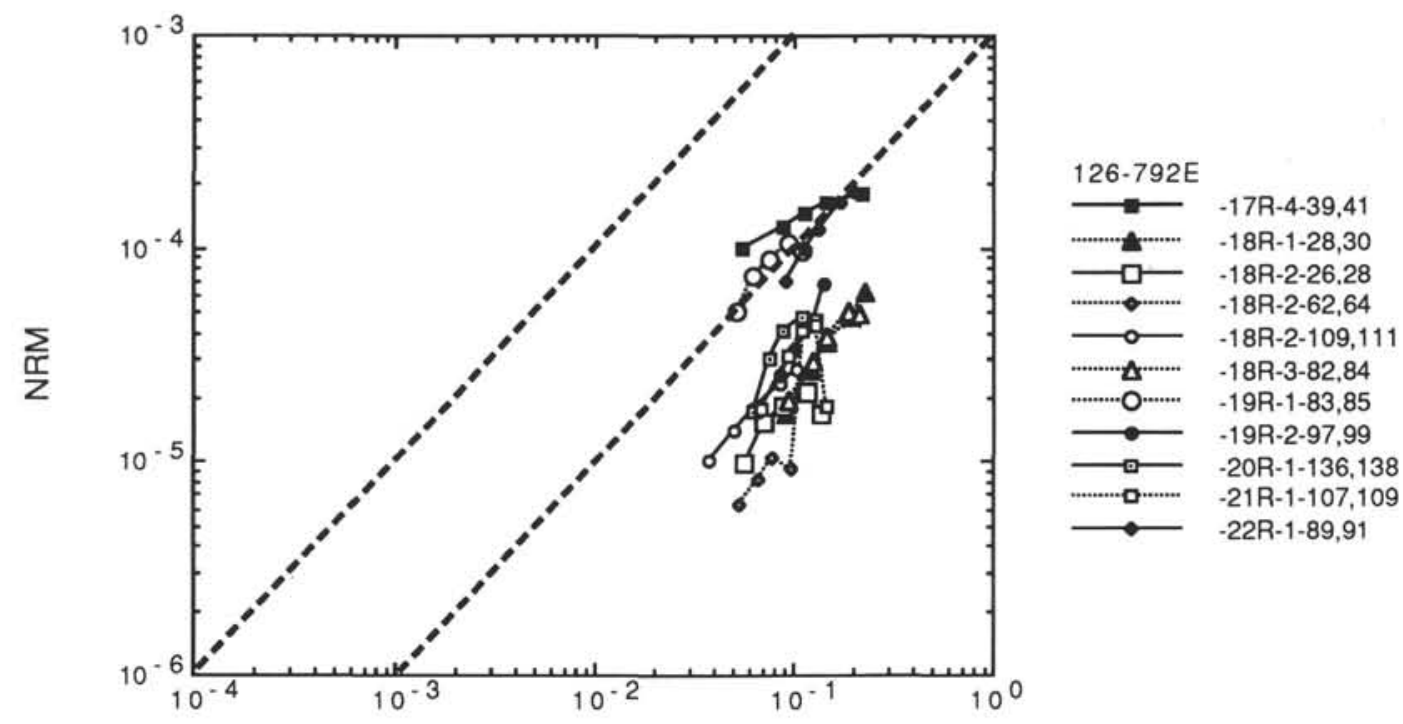

IRM

B.

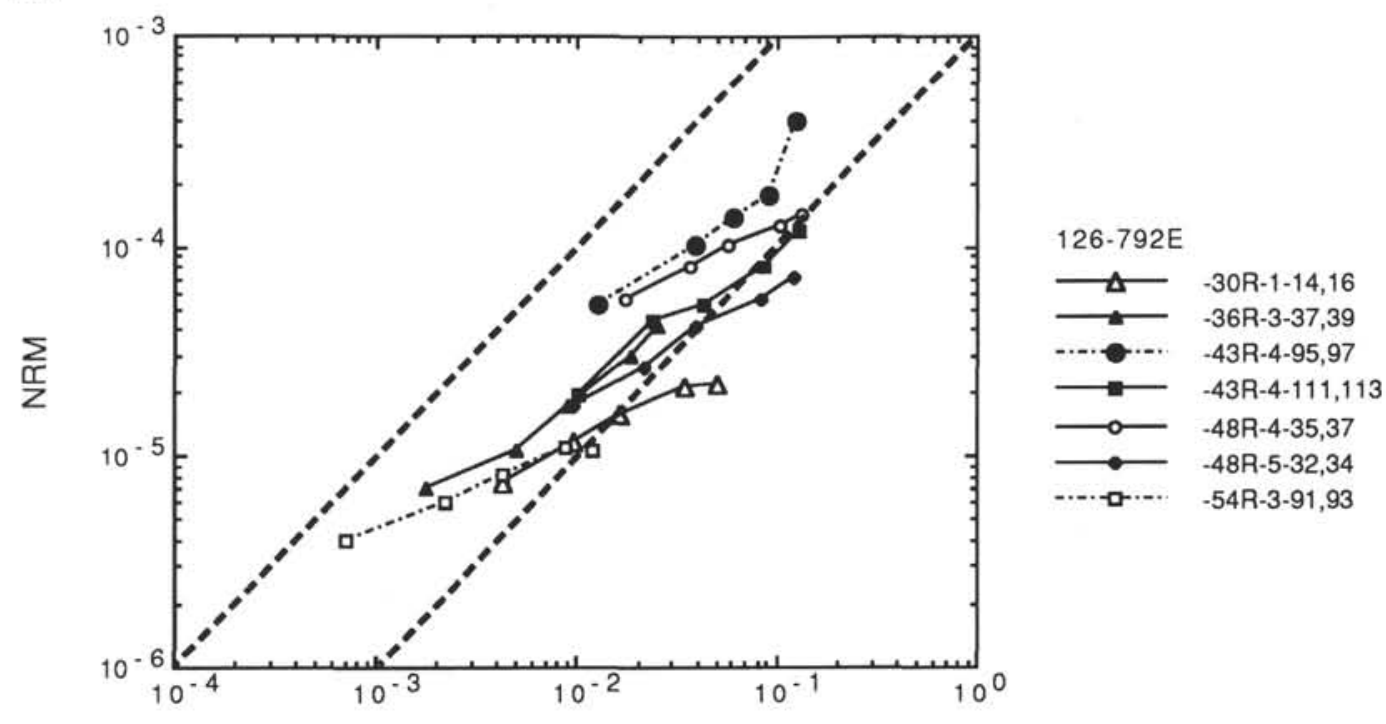

IRM

Figure 7. A. NRM vs. IRM alternating-field (AF) demagnetization responses for sediments from Hole 792E deposited during the Miocene (burial depths from 299 to $344 \mathrm{mbsf}$ ). Open symbols = samples with reversed inclinations following $\mathrm{AF}$ demagnetization; filled symbols $=$ normal inclinations. Line codes same as in Figure 1. B. NRM vs. IRM AF demagnetization responses for lithified sediments from Hole $792 \mathrm{E}$ deposited during the Oligocene (burial depths from 415 to $650 \mathrm{mbsf}$ ). Dashed-dotted line indicates composite (siltstone and sandstone) samples. 
A.

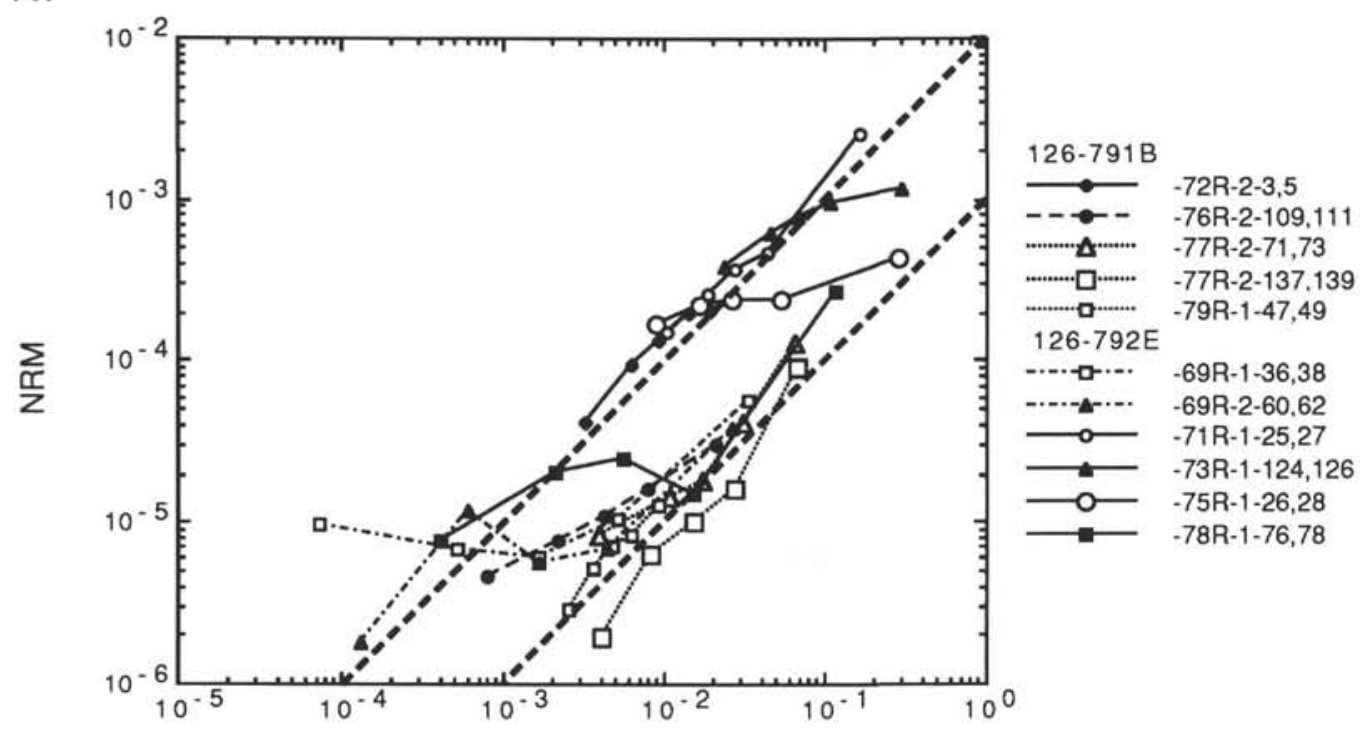

IRM

B.

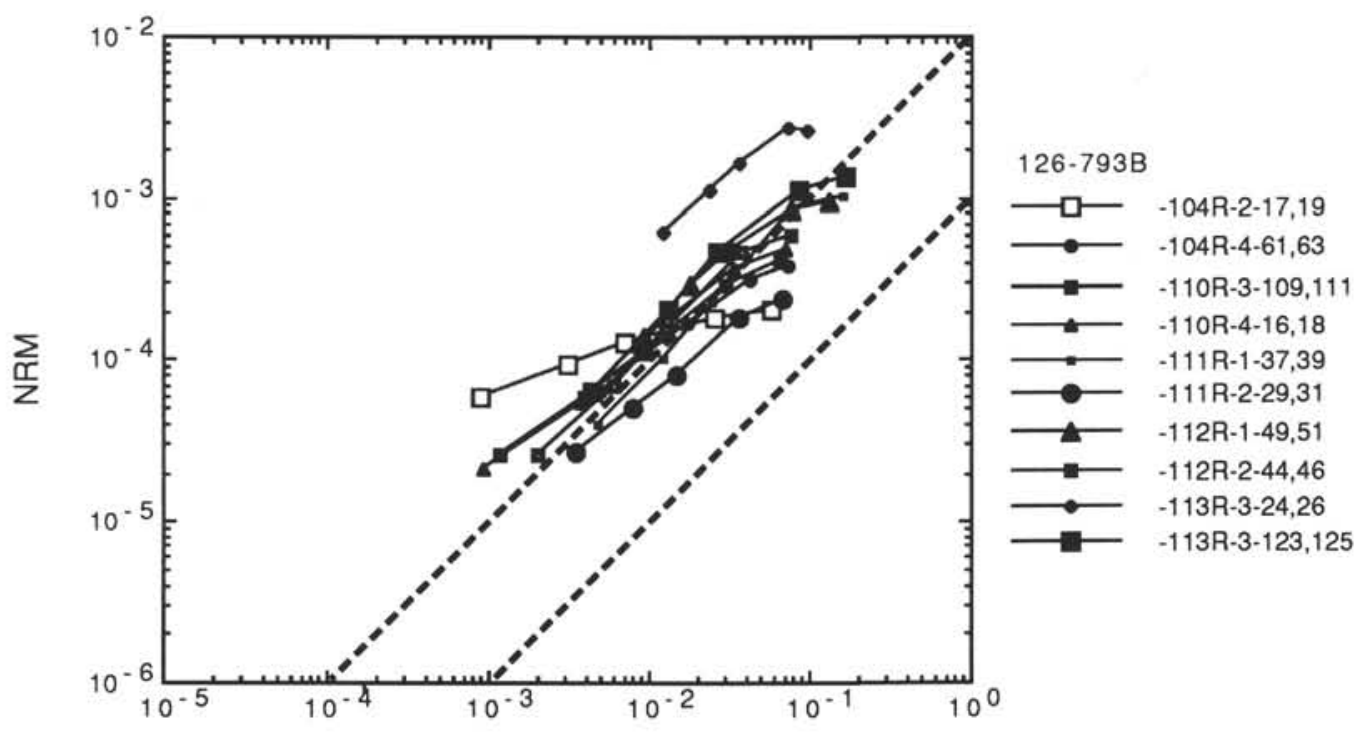

IRM

Figure 8. A. NRM vs. IRM alternating-field (AF) demagnetization responses for igneous rocks and pyroclastic sediments from Holes 791B and 792E. Solid lines = glassy brecciated basalt sample (Hole 791B) that lithified at high temperature (Koyama et al., this volume), and moderately altered andesites (Hole 792E). Dashed line $=$ diabase with glass and olivine altered to smectite. Dotted lines $=$ tuffs altered to chlorite. Dashed-dotted lines = severely altered volcanic conglomerates which probably lithified at low temperatures (Taylor, Fujioka, et al., 1990). Open symbols = samples with reversed inclinations after demagnetization; filled symbols $=$ normal inclinations. Dashed diagonal lines $=$ NRM/IRM ratios of 10-2 and 10-3, respectively. Intensities are in $\mathrm{kA} / \mathrm{m}$. B. NRM vs. IRM AF demagnetization responses for moderately altered basaltic andesites from Hole 793B. 


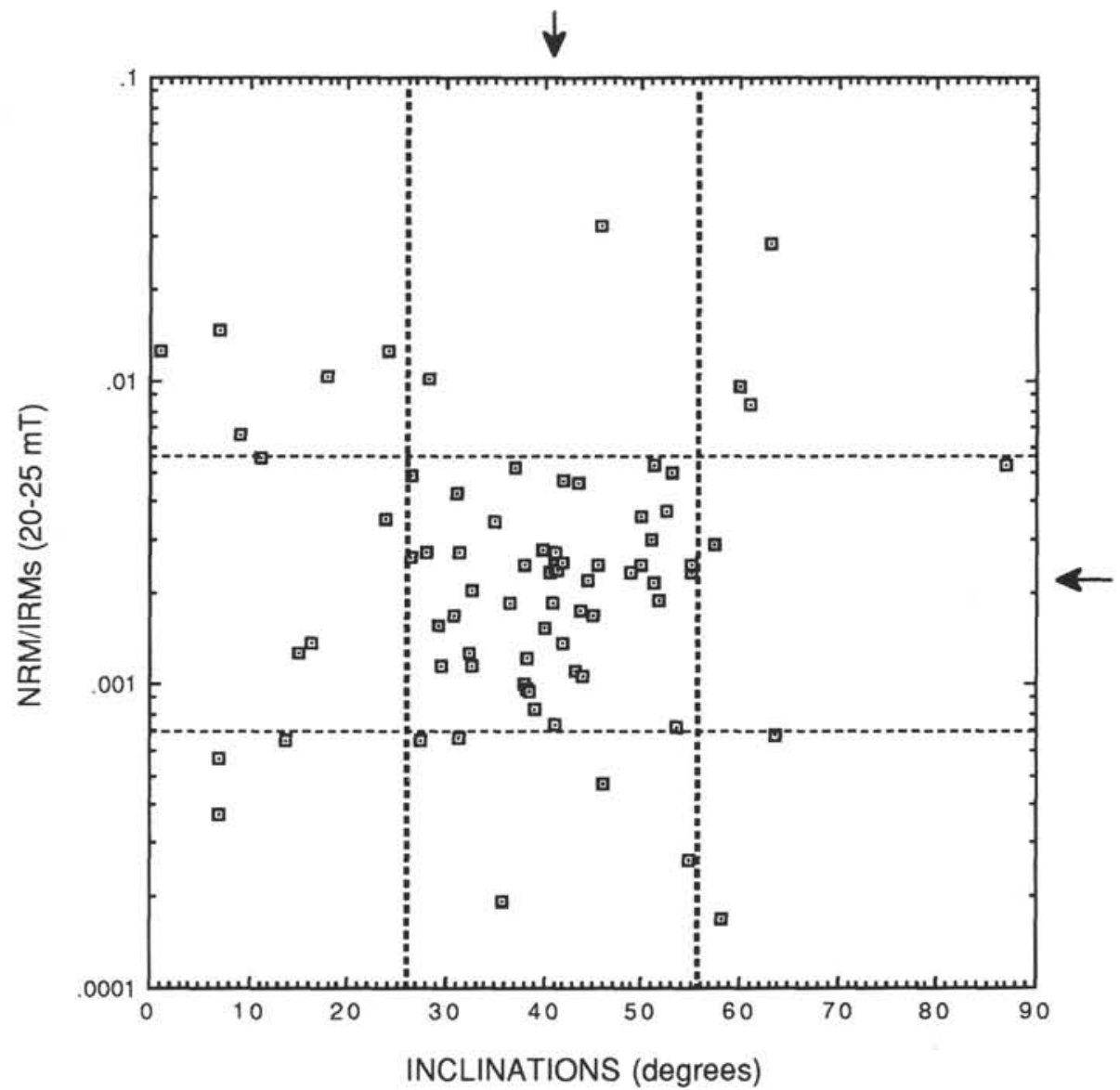

Figure 9. NRM/IRM ratios vs. inclinations (after AF demagnetization to 20 or $25 \mathrm{mT}$ ) for "Brunhes normal" samples from Site 790 to 793 . Arrows indicate present-day field inclination and median ratio values. Dashed lines indicate a $30^{\circ}$ range of inclinations and a factor of 8 distribution about these values. 